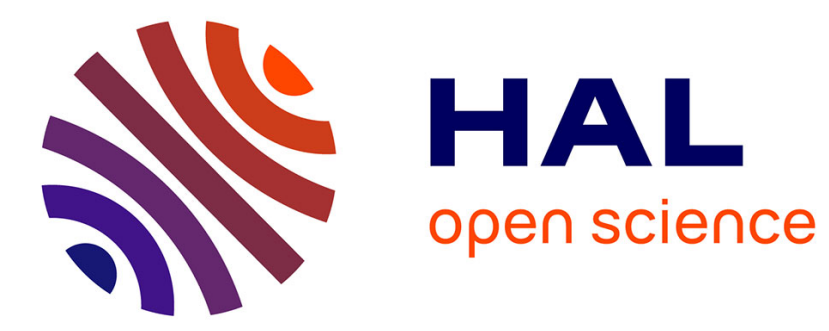

\title{
Mechanisms underlying transitional and turbulent boundary layer (TBL) flow-induced noise in underwater acoustics (II)
}

\author{
R. Katz, T. Galib, J. Cembrola
}

\section{> To cite this version:}

R. Katz, T. Galib, J. Cembrola. Mechanisms underlying transitional and turbulent boundary layer (TBL) flow-induced noise in underwater acoustics (II). Journal de Physique IV Proceedings, 1994, 04 (C5), pp.C5-1063-C5-1066. 10.1051/jp4:19945233 . jpa-00252920

HAL Id: jpa-00252920

https://hal.science/jpa-00252920

Submitted on 1 Jan 1994

HAL is a multi-disciplinary open access archive for the deposit and dissemination of scientific research documents, whether they are published or not. The documents may come from teaching and research institutions in France or abroad, or from public or private research centers.
L'archive ouverte pluridisciplinaire HAL, est destinée au dépôt et à la diffusion de documents scientifiques de niveau recherche, publiés ou non, émanant des établissements d'enseignement et de recherche français ou étrangers, des laboratoires publics ou privés. 


\title{
Mechanisms underlying transitional and turbulent boundary layer (TBL) flow-induced noise in underwater acoustics (II)
}

\author{
R.A. KATZ, T. GALIB* and J. CEMBROLA* \\ Naval Undersea Warfare, Center Detachment, New London CT 06320, U.S.A. \\ * Naval Undersea Warfare, Center Division, Newport RI 02841, U.K.
}

\begin{abstract}
This research applies dynamical system methods (i.e., Chaos Theory) to the processing of time sequences of transitional and turbulent wall-pressures impinging on the face of station probes mounted along the wall of an axisymmetric body of revolution during a buoyant ascent from the bottom of a deep water test basin. It is demonstrated that the turbulent pressure fluctuations for this experiment can be described as a dy namical system of sufficiently low order (i.e., less than ten degrees of freedom). This opens up several possibilities for the control of turbulence. In underwater acoustics this translates to flow noise reduction in sonar applications and to drag reduction in ship dynamics. Other potential commercial applications include control of flow through pipelines, and aerodynamic design
\end{abstract}

\section{EXPERIMENTATION}

The tests were conducted on a buoyantly-propelled, 21-inch diameter, axisymmetric test vehicle in Lake Pend Oreille, a deep water lake in northern Idaho. ${ }^{1}$

The test vehicle made a vertical ascent from the bottom of the deep water basin. A schematic of the test design is presented in Figure 1. The vehicle was hauled down to a depth of 1100 feet via a winch located on shore. Once the vehicle reached full depth, the vehicle electronics and tape recorder activated automatically to allow ambient measurements to be recorded. After a short time interval, the vehicle released itself and ascended toward the surface, reaching (very near) terminal velocity (steady-state conditions) in a few seconds. At a depth of 150 feet, the control fins were activated so that the vehicle would turn to a horizontal position before reaching the surface. Vehicle speed was set on shore by changing cylindrical lead weights in the ballast section of the vehicle. In this way, approximate steady state velocities varying between $12 \mathrm{and} 22 \mathrm{~m} / \mathrm{sec}$ were attainable.. Data used for analysis were taken from the constant velocity portion of the run; constant velocity data endured from 6 to 15 seconds, depending on vehicle speed.

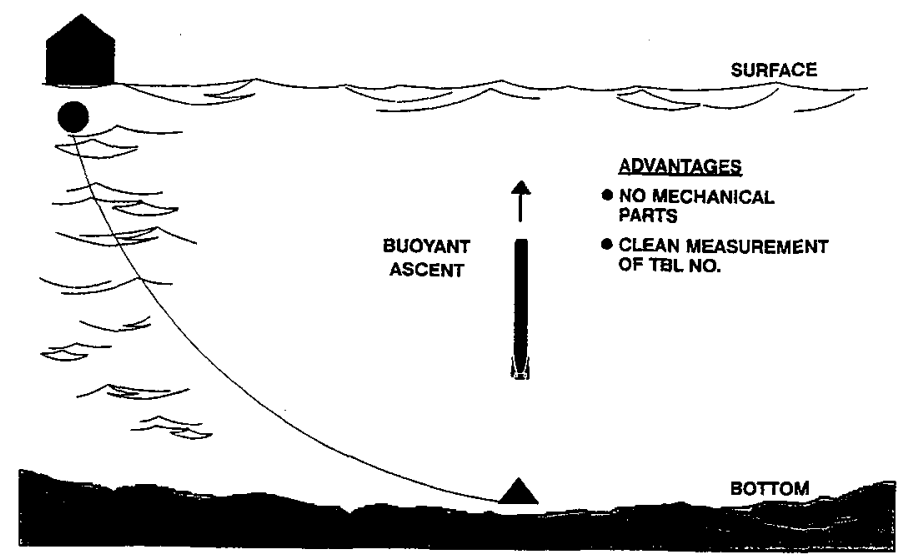

Figure 1. Buoyant test vehicle experimental design 
The 'length' Reynolds number is determined from a characteristic length based on the distance from the stagnation point at the leading edge of the centerline axis to the projected normal to the centerline from a measurement point along the body surface. These lengths are illustrated in Figure 2 and it is readily seen that lengths vary from .5 to 1.16 feet depending on probe position. Considering the range of vehicle velocities $\left(\mathrm{u}_{\infty}\right)$ between 39 and $72 \mathrm{ft} / \mathrm{sec}$, one obtains a range of values for the length Reynolds number between 1.1 and $4.9 \times 10^{6}$ based on a kinematic viscosity $v$ of $1.69 \times 10^{-5} \mathrm{ft}^{2} / \mathrm{sec} @ 39^{\circ} \mathrm{F}$, and where $R=\left(1 u_{\infty}\right) / v$.
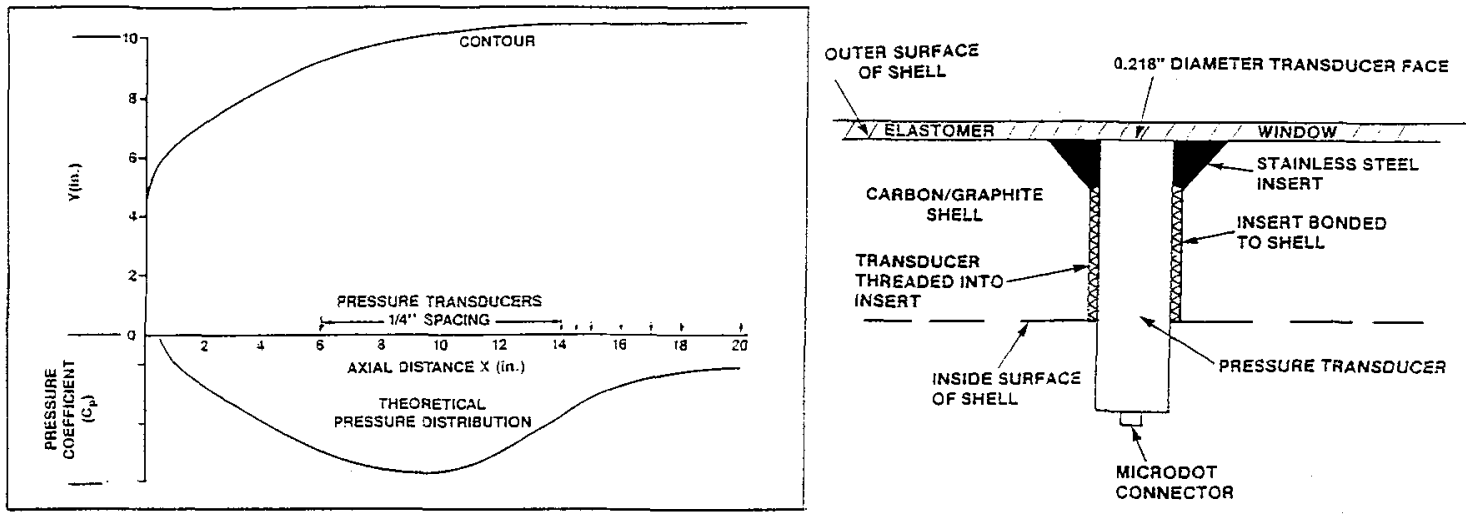

Figure 2. Pressure transducer spacing and gradient characteristics

\section{DATA PROCESSING}

Time sequences of the wall-pressure measurements taken at various station positions were recorded in analog format and converted to digital records of approximately 10,000 and 60,000 samples each at approximate sample rates of $10 \mathrm{kHz}$ and $60 \mathrm{kHz}$ respectively. The pressure sensor had a built-in high pass filter to remove low frequency components below $150 \mathrm{~Hz}$. These time sequence measurements are believed to be representative of the 'system dynamics' where system in this context includes both transitional and turbulent (or transitional) pressures and measuring apparatus. Although the measuring apparams includes two filters through which the turbulent energy must pass(namely, the area on the face of the transducer acts as a spatial filter and the wall layer at the surface acts as an attenuator ${ }^{2}$ ) the dynamical behavior of the measured turbulence is still believed to be well preserved.

Power spectral densities obtained from time-sequences of the measured wall-pressures are provided in Figure 3 as a function of the non-dimensional Strouhal number and as a function of downstream probe position (going from top to bottom of figure). The expected frequency zone of peak amplifications are indicated by the vertical lines in each graph, as determined from Orr-Sommerfeld model predictions, and are in sound agreement with the actual measurements, particularly in the transition zones where the so called Tollmien-Schlicting (T-S) instability modes are most expected. Note, however the evident breakdown to T-S modes in the temporal power spectrum following the spatial migration into the fully developed turbulence region of the flow.

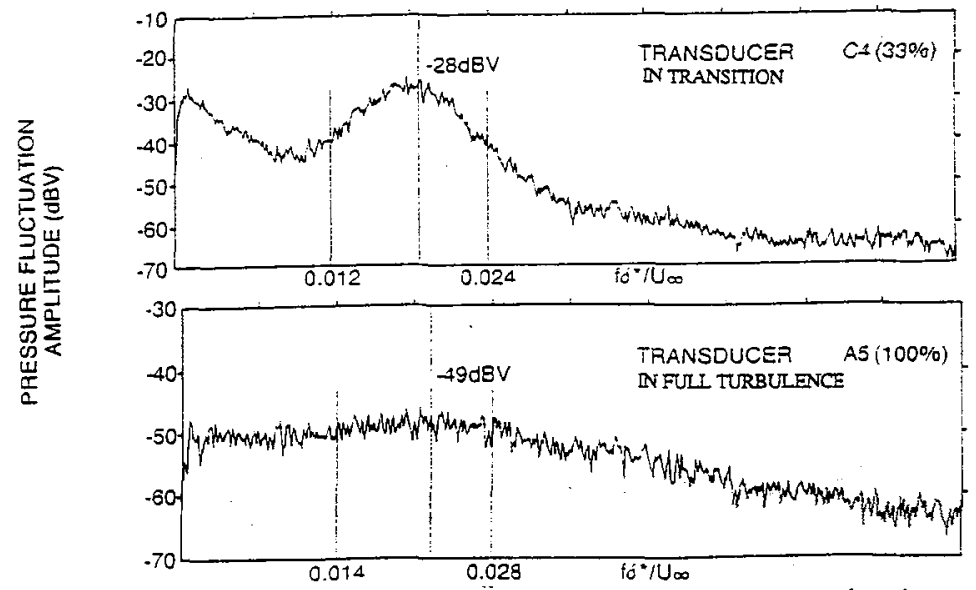

Figure 3. Temporal power spectra at various downstream locations 
Using the standard delay embedding technique, phase portrait constructions were obtained from transitional and turbulence time sequence measurements. The smaller sample rate data are provided for illustration. Some orbital cleaning of the turbulence time sequences was achieved by low pass filtering beyond the region of T-S frequencies. Representative phase plots ( in Figure 3 ) for transition zone and turbulence zone time sequence measurements show striking similarity following low pass filtering of the turbulence data. The coalescing of points at a delay interval of $T=5 \times 10^{-4}$ is evidence of the stroboscropic orbit of the T-S wave, shown here at $1 / 2$ wavelength. The similarity in data structure between transitional and turbulence measurements is clearly not observed using the linear data processing technique (i.e., temporal power spectrum).
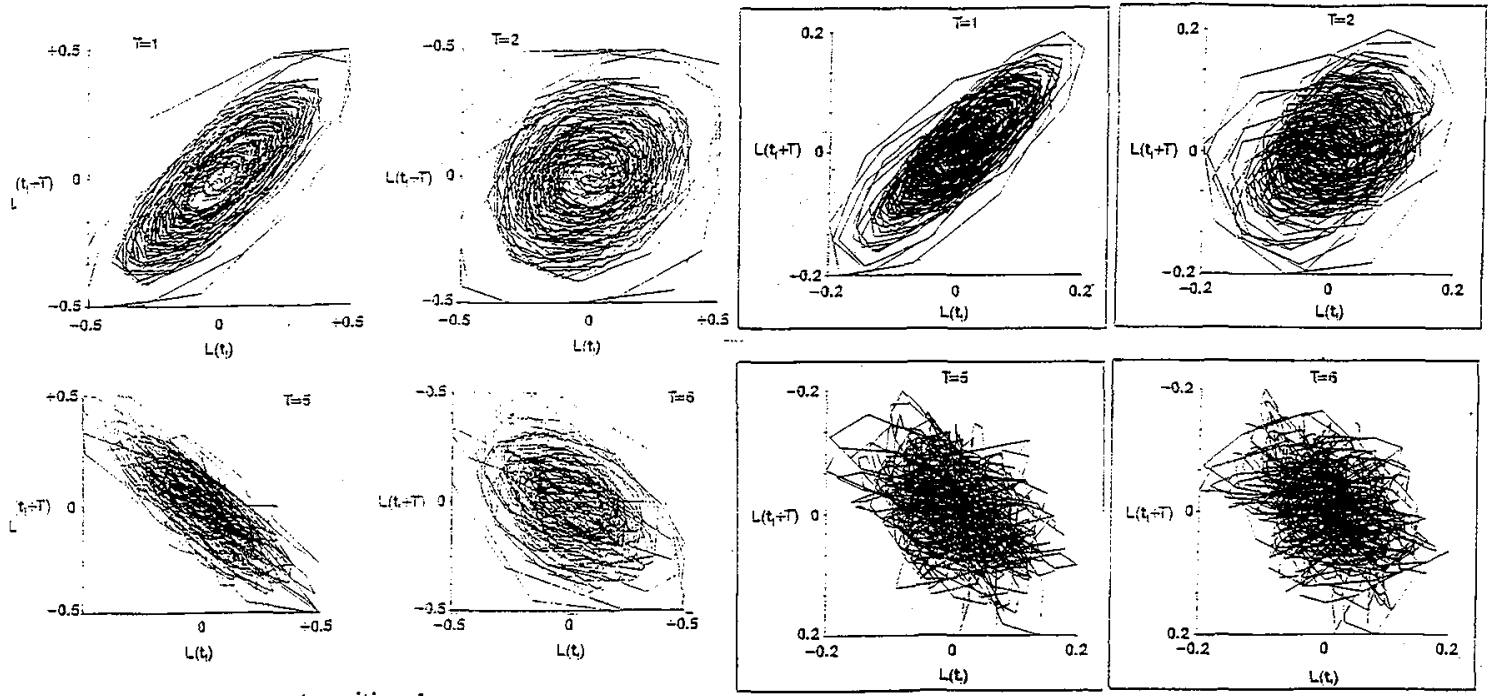

transitional

full turbulence

Figure 4. Phase portraits obtained from time sequence measurements (delay=Tx10-4)

For the larger sample rate data, the minimum embedding was computed for various station measurements, by applying the false-neighbor technique, using the software provided by $\mathrm{H}$. Abarbanel and $\mathrm{T}$. Frison. ${ }^{3}$ The results for a turbulence station probe are provided in Figure 4. which shows a solution convergence approaching an embedding of dimension 6 . Further calculations performed by Abarbanel and Frison indicate a maximum value of 8 for a turbulence station measurement, a value of 6 for a transition station measurement, and something of very high order (non-convergent) for a laminar station measurement. This is consistent with expected boundary layer theory results, when considering that: (a) transitional T-S modes in and of themselves are lower order than fully developed turbulent modes; and (b), the measured fluctuations in the laminar zone are more apt to be representative of system level noise rather than the turbulence itself (i.e., true laminar flow is devoid of perturbations).

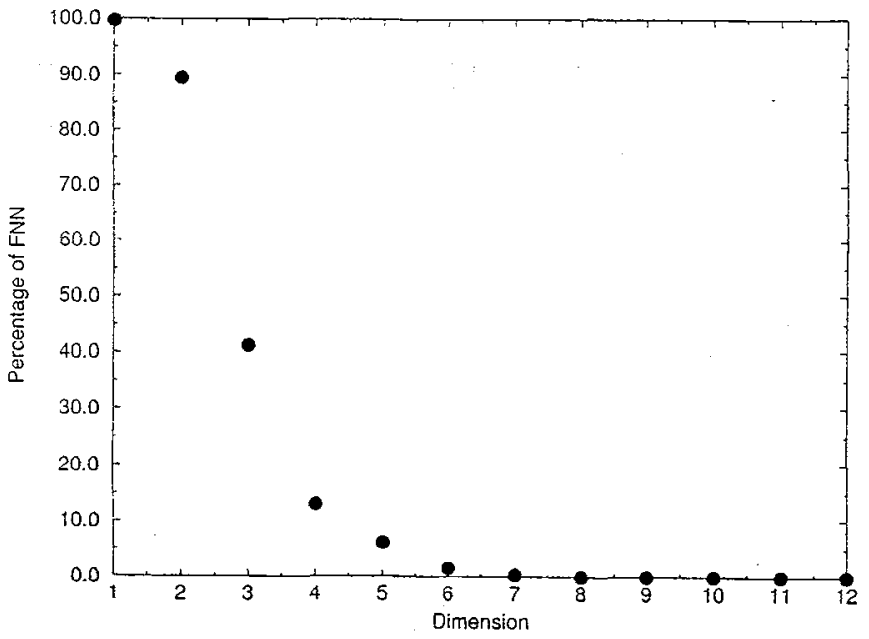

Figure 5. Minimum embedding of tubulent time sequence (after, Abarbanel and Frison) 
Various station measurements of the wall-pressure time sequences were analyzed using the wavelet transform, using $R$. Everson's software code employing the Mexican hat wavelet. ${ }^{4}$ Results, to date, indicate no obvious connection in selfsimilarity between transitional and turbulent data sets using this particular wavelet although self similarities were found to exist within a particular data set. An example of the wavelet transform applied to a turbulence time sequence measurement is provided in Figure 5 . Further investigations are proceeding using other wavelet types such as Morlet's to explore phase content of the signal. This research is in process.

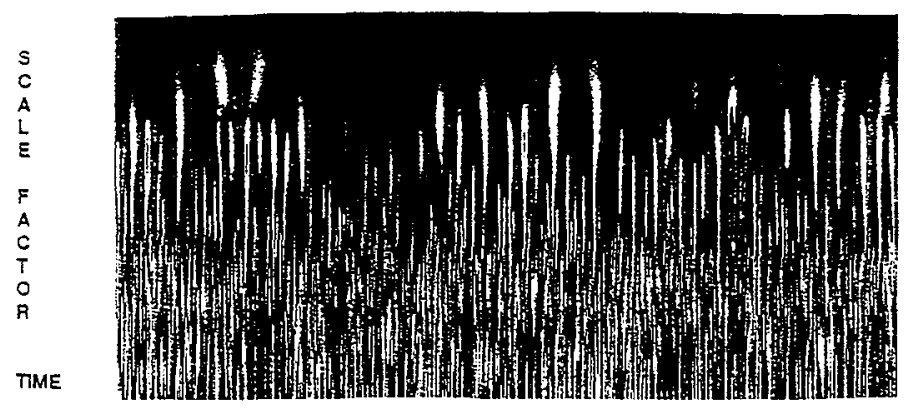

Figure 6. Wavelet transform of turbulence time sequence (after, Everson)

\section{SUMMARY AND CONCLUSIONS}

Time sequences of wall-pressure fluctuations were obtained from station probes mounted along the wall of an axisymmetric body during vertical ascent from a deep water test basin. Sampled recordings of the transitional and turbulent fluctuations were processed to produce digital time sequences, from which temporal power spectra, phase portrait constructions, minimum embedding and wavelet transforms were obtained. The wavelet transform analysis, to date, is inclusive. Selfsimilarity in the wavelet structure is evident within a particular region of the flow (i.e., transition or turbulence) but not between regions. The power spectra obtained from these field measurements show amplification of Tollmien-Schlicting (TS) modes consistent with Orr-Sommerfeld Theory. Interestingly, phase portrait constnuctions show evidence of a persistence of the T-S wave structure beyond the initial state of transition that is not evident in the power spectrum. This low order persistence into the turbulent region of the flow is further supported by a minimum embedding computation of 8 obtained from a station probe in the fully developed tubulence region. The evidence of low dimensionality in the fully turbulent zone opens up several new possibilities for turbulence control for systems of the type described by this experiment from flow-noise suppression to drag control, to wide-spread commercial uses such as control of flow through pipe lines and aerodynamic control. Additional research is warranted to (a) substantiate further theses findings and (b) develop and implement adaptive control mechanisms for these engineering applications.

\section{ACKNOWLEDGMENTS}

This research was performed at the Naval Undersea Warfare Center under contract number 793P13, Special Projects Initiative, Science and Technology Directorate, Code 10 (Dr. William Roderick) Program Sponsor. The authors wish to thank the following individuals for their special contributions to this effort: Dr. H. Abarbanel, Institute for Nonlinear Science, UCSD snd T. Frison, Randle, Inc; Dr. M. Maxey and Dr. R. Everson, Center for Fluid Mechanics, Turbulence, and Computation, Division of Applied Mathematics, Brown University; Dr. R. Handler, Naval Research Lab; and Dr. J. Salisbury, Analysis and Technology, Inc.

\section{REFERENCES}

1. R.A. Katz and M. Maxey, "Mechanics underlying transitional and turbulent boundary layer (tbl) flow-induced noise in underwater acoustics," Proceedings of the 14th International Congress on Acoustics, Vol.1, B6-8, September 1992.

2. T.A. Galib, R. A. Katz, S. Ko, B. Sandman, "Measurements of turbulent pressure fluctuations using a buoyant vehicle with a thin elastomer layer," JASA Preprint June 1993.

3. H.D.I. Abarbanel, M.B. Kennel, "Local False Nearest Neighbors and Dynamical Dimensions for Observed Chaotic Data," Institute for Nonlinear Science INLS Report, University of California, San Diego, October 1992.

4. Private communications, NUWC and Center for Fluid Mechanics, Turbulence, and Computation, Brown University. 